University of Wollongong

Research Online

Faculty of Social Sciences - Papers (Archive) Faculty of Arts, Social Sciences \& Humanities

2007

The impact of a cancer diagnosis on the health behaviors of cancer

survivors and their family and friends

\author{
Nancy Humpel \\ University of Wollongong, humpel@uow.edu.au \\ Christopher Magee \\ University of Wollongong, cmagee@uow.edu.au \\ Sandra C. Jones \\ University of Wollongong, sandraj@uow.edu.au
}

Follow this and additional works at: https://ro.uow.edu.au/sspapers

Part of the Education Commons, and the Social and Behavioral Sciences Commons

Research Online is the open access institutional repository for the University of Wollongong. For further information contact the UOW Library: research-pubs@uow.edu.au 


\title{
The impact of a cancer diagnosis on the health behaviors of cancer survivors and their family and friends
}

\begin{abstract}
Goals The aim of this study was to examine the effect of a cancer diagnosis on the health behaviors of cancer survivors and their family and friends, and to determine whether a cancer diagnosis could be a teachable moment for intervention. Materials and methods This was a cross-sectional study of the health behaviors of individuals taking part in a cancer fundraising event. The questionnaire was completed by 657 participants. Main results Participants were $81.4 \%$ women, had a mean age of 46 years, and comprised of $17.2 \%$ cancer survivors. For cancer survivors, $31.3 \%$ reported an increase in physical activity, $50 \%$ of smokers quit, and 59 to $72 \%$ reported dietary improvements within 1 month of diagnosis. Significant differences in behavior change were found by age, but not by gender or education. For individuals without cancer, $24.3 \%$ reported improved physical activity and the majority reported some dietary changes. A greater proportion of family and friends who perceived they were at greater risk of developing cancer increased physical activity and sun-smart behavior but did not improve dietary habits. Conclusions The results indicate that the cancer survivors made significantly more positive health behavior changes compared to the non-cancer group. For this sample, a personal diagnosis of cancer, or a diagnosis in a family member or friend, may have acted as a 'cue to action' to improve lifestyle health behaviors. This field of research is still at an early stage, and further studies are needed to confirm if this situation could be useful as a 'teachable moment' for intervention purposes.
\end{abstract}

\section{Keywords}

health, cancer, friends, impact, survivors, their, family, diagnosis, behaviors

\section{Disciplines}

Education | Social and Behavioral Sciences

\section{Publication Details}

Humpel, N., Magee, C. \& Jones, S. C. (2007). The impact of a cancer diagnosis on the health behaviors of cancer survivors and their family and friends. Supportive Care in Cancer, 15 (6), 621-630. 
The impact of a cancer diagnosis on the health behaviors of cancer survivors and their family and friends

Nancy Humpel $^{1}$, Christopher Magee ${ }^{2}$ and Sandra C. Jones ${ }^{1}$

(1) Centre for Health Behaviour and Communication Research, Faculty of Health and Behavioural Sciences, University of Wollongong, Wollongong, New South Wales, 2522, Australia

(2) School of Psychology, Faculty of Health and Behavioural Sciences, University of Wollongong, Wollongong, New South Wales, Australia

\begin{abstract}
Goals

The aim of this study was to examine the effect of a cancer diagnosis on the health behaviors of cancer survivors and their family and friends, and to determine whether a cancer diagnosis could be a teachable moment for intervention.
\end{abstract}

\title{
Materials and methods
}

This was a cross-sectional study of the health behaviors of individuals taking part in a cancer fundraising event. The questionnaire was completed by 657 participants.

\section{Main results}

Participants were $81.4 \%$ women, had a mean age of 46 years, and comprised of $17.2 \%$ cancer survivors. For cancer survivors, $31.3 \%$ reported an increase in physical activity, $50 \%$ of smokers quit, and 59 to $72 \%$ reported dietary improvements within 1 month of diagnosis. Significant differences in behavior change were found by age, but not by gender or education. For individuals without cancer, $24.3 \%$ reported improved physical activity and the majority reported some dietary changes. A greater proportion of family and friends who perceived they were at greater risk of developing cancer increased physical activity and sun-smart behavior but did not improve dietary habits. 


\section{Conclusions}

The results indicate that the cancer survivors made significantly more positive health behavior changes compared to the non-cancer group. For this sample, a personal diagnosis of cancer, or a diagnosis in a family member or friend, may have acted as a 'cue to action' to improve lifestyle health behaviors. This field of research is still at an early stage, and further studies are needed to confirm if this situation could be useful as a 'teachable moment' for intervention purposes.

Keywords: Cancer Physical activity Exercise Diet Health behavior 


\section{Introduction}

An ageing population combined with advances in early detection and treatments have resulted in an everincreasing number of cancer survivors. The number of new cancer diagnoses each year is estimated at 1.3 million in the USA [1] and 85,000 in Australia [5]. Recent improvements in diagnosis and treatment have meant that more people are surviving cancer, and the survival rate for breast and prostate cancer has reached 85\% in Australia [44]. As a consequence, there are currently 9.6 million cancer survivors in the USA [1] and 268,000 in Australia [5], and these numbers are expected to rise by $25 \%$ over the next decade [44]. Unfortunately, many cancer treatments are toxic in nature, increasing the risk of other medical problems such as cardiovascular disease, osteoporosis, and diabetes [21]. Survivors are also prone to cancer recurrence [39], impairments in functional capacity [26], sleep disturbances [7, 20, 22], depression [16, 20, 41], and poor quality of life. Furthermore, a recent Australian study compared non-cancer mortality rates of cancer patients to those of the general population and found cancer patients were nearly $50 \%$ more likely to die of non-cancer causes [6]. The health and well-being of cancer survivors is, therefore, a considerable concern for health practitioners and researchers.

Research over the past decade has demonstrated that increases in physical activity and improvements in diet are practical and effective ways to reduce the health problems faced by cancer survivors $[14,17,19,31,32$, 35]. An important life transition or a life-threatening health problem such as cancer diagnosis has been referred to as a 'teachable moment' and can be viewed as a 'cue to action' in relation to making positive changes to health behaviors $[29,30]$. The majority of cancer survivors appear concerned with improving their physical health. In a US study about cancer patients' readiness to pursue lifestyle changes, $80 \%$ indicated an interest in health promotion programs generally, with 50-60\% reporting interest in the areas of diet and exercise specifically [18]. 
Despite this, many cancer survivors continue to engage in unhealthy lifestyle behaviors that could place them at risk of further health problems [38]. Several studies have examined the current prevalence of health behaviors post diagnosis $[8,13,18,36]$. For example, a study of the current dietary intake found that $31 \%$ of the cancer survivors did not meet the fat intake guidelines and 58\% did not eat sufficient serves of fruit and vegetables [18]. Studies of changes in behavior since diagnosis have found some changes in dietary behaviour. One study found that 50.6\% had reduced their fat intake, $43.5 \%$ had increased their fiber intake, 42.9\% had reduced their red meat intake, and $46 \%$ had quit smoking since diagnosis [9]; another reported that $45.1 \%$ were eating more fruit and vegetables, $26.4 \%$ eating less red meat, and $28.5 \%$ were eating less fat since diagnosis [34]. A further study found breast cancer survivors reporting a 77\% increase in fruit and vegetable consumption [28], and a longitudinal study of colon cancer survivors found at 2 years post diagnosis a significant increase in vegetable intake [42].

On the other hand, studies that have examined physical activity levels in cancer survivors have reported lower proportions making improvements. One study found that $70 \%$ did not meet the minimum recommendations for physical activity [8], another found that $42 \%$ of the survivors were not routinely exercising [18], another 58\% were not exercising regularly [39], another study found that $64 \%$ were not exercising regularly [2], and a further study found that only $20.8 \%$ of the survivors increased their physical activity levels since diagnosis [34], and one study reported that $30.6 \%$ had decreased physical activity levels [9].

This suggests that a cancer diagnosis may have a positive impact on some lifestyle behaviors (e.g., diet), but a negative impact on others (e.g., physical activity levels). Positive lifestyle changes are more likely to occur if the cancer survivor believes that these changes will improve their health and prevent cancer reoccurrence [40]. Because cancer survivors seem amenable to making positive changes in their lifestyles to improve their health, it has been suggested that the diagnosis of cancer could serve as a 'teachable moment' for making health behavior changes [25]. In terms of cancer, a 'teachable moment' would provide an opportunity for 
targeted health programs to take advantage of these moments to improve the health and well-being of cancer survivors $[8,18,29,34]$. More research is needed, however, examining variables that may be associated with changing health behavior so that more targeted and effective health programs can be developed.

There is also a possibility that the diagnosis of cancer could serve as a 'teachable moment' for the family of breast cancer survivors, as these individuals could realize the risks of cancer and be motivated to make positive lifestyle changes $[4,25,40]$. This notion has received some support as the female relatives of cancer survivors appear aware of risk factors for cancer [24], are more likely to engage in regular physical activity [4], and have regular mammograms than women without a family history of cancer [27]. Lemon et al. [25] found that $42 \%$ of the first-degree female relatives (FDFR) of women with breast cancer reported making at least one positive health behavior change in the first 6 months post diagnosis. However, in terms of smoking and fruit and vegetable intake, women at familial risk of cancer also show a trend towards more unhealthy behaviors, which is an area of concern [27]. Although limited by a small sample, Rabin and Pinto [40] also found some evidence indicating that female relatives made positive changes if they perceived cancer as a health risk to themselves.

These studies tentatively suggest that the diagnosis of cancer could serve as a 'teachable moment' not only for cancer survivors, but also for their family. However, this has only been examined in FDFR of breast cancer patients, and there is no indication of how a cancer diagnosis affects male family members. There is also no indication of whether the diagnosis of cancer has an impact on the friends of cancer survivors. If cancer were to represent a 'teachable moment' for both family and friends, it could pave the way for more targeted and effective health programs aimed at improving general health across a greater segment of the population.

The aim of the current study was, therefore, to examine the effects of cancer diagnosis on the lifestyle behaviors of cancer survivors and the family and friends of cancer survivors. Important factors such as age, 
gender, time since diagnosis, education level, and marital and work status were included to investigate variables that may be implicated in behavior changes. Further, whereas most prior studies have measured the 'current dietary' intake and physical activity levels post diagnosis, few have inquired about 'changes' following diagnosis, and no studies were found that inquired about changes in sun-safe behavior. Because it is increasingly important to measure multiple behavior changes, the current study focussed on changes in diet (fat, fruit/vegetable, etc. consumption), smoking, physical activity, and sun-safe behaviors, as these are all implicated to varying degrees in cancer outcomes.

\section{Materials and methods}

\section{Participants and procedure}

Participants were recruited through a series of cancer fundraising events (Cancer Council Relay for Life) held throughout New South Wales, Australia, in 2005. The advantage of this event is that participants include cancer survivors and the friends and family of cancer survivors. It also comprises of a relatively large and diverse sample from which to recruit participants.

Approximately 5,000 surveys were made available to the organizers of the fundraising events. The survey package was sent to individuals who had registered to participate in the event. Potential participants were asked to complete the anonymous survey and then return it to the researchers in a reply-paid envelope. It is difficult to estimate the actual number of participants who received a survey package because the researchers were not actively involved in the distribution of the surveys, and some may have been lost or not distributed. A total of 657 participants completed the questionnaire, which indicated that $13.1 \%$ of the surveys were completed. Due to a lack of final distribution numbers, the true response rate is difficult to determine. The study was approved by the Cancer Council and the University of Human Research Ethics Committee. 


\section{Measures}

All participants completed a questionnaire that included items measuring age, gender, marital status, education, current employment status, current physical activity levels, and changes in health behaviors. Participants were asked to indicate whether they had been diagnosed with cancer, and if so, to specify the type of cancer, whether they were still receiving treatment, and the time since diagnosis. Non-cancer participants were asked whether they had any family and/or friends who had been diagnosed with cancer, and if so, to specify the number of family and friends diagnosed, and the time since the most recent diagnosis. These participants were also asked to indicate their perceived risk of ever getting cancer on a fivepoint response scale [43].

The Active Australia Survey was used to measure physical activity levels and included items regarding the amount of walking, other moderate activity, and vigorous activity engaged in during the week before completing the questionnaire. These three physical activity types were summed to provide an indication of the total physical activity each week. This measure has provided reliable and valid indices of physical activity levels in previous national Australian surveys [10, 11].

Participants were then asked whether the cancer diagnosis (either their own or a family member's or friend's) influenced changes in their diet (the amount of fat, fiber, fruits, and vegetables, takeaway) and sun protection behavior and when these changes had occurred (within 1 month, 6 months, much later, or never). The participants were asked to indicate whether they did more, less, or had not changed the amount of physical activity they did since the diagnosis of cancer. These items were based on those used in a previous study [9]. The participants were also asked whether they had been smoking at the time of the diagnosis and whether or not they had quit.

\section{Results}


There were $81.4 \%$ female participants, and the mean age was 46 years $(\mathrm{SD}=15)$. The characteristics of the cancer survivors and individuals without a cancer diagnosis are included in Table 1. Cancer survivors made up $17.2 \%$ of the population, and breast cancer was the most common type of cancer followed by melanoma and cervical cancer (see Table 2). For individuals without a cancer diagnosis, $18.7 \%$ reported having no family members with cancer, $27.8 \%$ one family member, $36.4 \%$ two to three family members, and $17.1 \%$ more than three family members. Furthermore, $31.4 \%$ reported having no friends with cancer, $25.1 \%$ reported one friend, $26.4 \%$ two to three friends, and $17.1 \%$ three or more friends with cancer. Only $4.3 \%$ of participants reported having no known friends or family diagnosed with cancer. In response to the diagnosis of a family or friend diagnosed with cancer, $26.9 \%$ of participants indicated that they had gone to a doctor for their own check-up.

Table 1. Characteristics of participants

\begin{tabular}{|c|c|c|c|c|c|c|}
\hline & Total sa & Perce & Cancer & Perc & Non & - Percent \\
\hline & $\mathrm{N}=657$ & & $\mathrm{~N}=113$ & & $\mathbf{N}=5$ & \\
\hline Gender & & & & & & \\
\hline Men & 122 & 18.6 & 15 & 13.2 & 107 & 19.7 \\
\hline Women & 535 & 81.4 & 98 & 86.7 & 437 & 80.3 \\
\hline Age & & & & & & \\
\hline$\leq 35$ & 165 & 25.0 & 6 & 5.3 & 158 & 29.1 \\
\hline $36-55$ & 295 & 44.9 & 51 & 45.1 & 244 & 44.9 \\
\hline$>55$ & 197 & 30.0 & 56 & 49.6 & 141 & 25.9 \\
\hline Education & & & & & & \\
\hline$\leq 10$ years & 232 & 35.3 & 46 & 40.7 & 186 & 34.2 \\
\hline
\end{tabular}




\begin{tabular}{|c|c|c|c|c|c|c|}
\hline & \multicolumn{6}{|c|}{ Total sample Percent Cancer survivors Percent Non-cancer Percent } \\
\hline & \multicolumn{2}{|l|}{$\mathrm{N}=657$} & \multicolumn{2}{|l|}{$\mathrm{N}=\mathbf{1 1 3}$} & \multicolumn{2}{|c|}{$\mathrm{N}=544$} \\
\hline 12 years/TAFE/trade & 221 & 33.6 & 37 & 32.7 & 184 & 33.8 \\
\hline Tertiary & 193 & 29.4 & 25 & 22.1 & 168 & 30.9 \\
\hline \multicolumn{7}{|l|}{ Work status } \\
\hline Student & 41 & 6.2 & 1 & 0.9 & 40 & 7.4 \\
\hline Full-time & 300 & 45.7 & 31 & 27.4 & 269 & 49.4 \\
\hline Part-time & 141 & 21.5 & 28 & 24.8 & 113 & 20.8 \\
\hline Home/retired/voluntee & 169 & 25.7 & 50 & 44.2 & 119 & 21.9 \\
\hline Unemployed & 5 & 0.8 & 2 & 1.8 & 3 & 0.6 \\
\hline
\end{tabular}

TAFE Technical and further education

Table 2. Cancer type, time since diagnosis, and treatment status

\begin{tabular}{|lcc|}
\hline & \multicolumn{2}{|c|}{ Number Percent } \\
\hline Cancer type & & \\
\hline Breast & 42 & 41.6 \\
\hline Melanoma & 15 & 14.9 \\
\hline Cervical & 11 & 10.9 \\
\hline Colon/rectal & 7 & 6.9 \\
\hline Ovarian & 6 & 5.9 \\
\hline Other & 16 & 19.8 \\
\hline
\end{tabular}




\begin{tabular}{|l|c|}
\hline \multicolumn{3}{|c|}{ Number Percent } \\
\hline Time since diagnosis \\
\hline Within 3 months 3 & 2.7 \\
\hline 3 months to 1 year 10 & 9.0 \\
\hline 1 to 2 years & 17.1 \\
\hline More than 2 years 79 & 71.2 \\
\hline Still undergoing treatment \\
\hline Yes & 27.0 \\
\hline No 30 & 73.0 \\
\hline
\end{tabular}

\section{Physical activity levels of participants}

Participants reported engaging in an average of $200(\mathrm{SD}=190)$ minutes of walking, $87(\mathrm{SD}=158)$ minutes of other moderate physical activity, and $106(\mathrm{SD}=152)$ minutes of vigorous physical activity in the previous week (see Table 3). The average total physical activity amount was $380(\mathrm{SD}=343)$ minutes a week.

Table 3. Mean minutes (SD) per week of each type of physical activity and by cancer diagnosis

\begin{tabular}{|l|l|l|l|l|l|}
\hline & Walking & Other moderate activity & Vigorous activity & Total physical activity \\
\hline Gender & & & & \\
\hline Males & $199(216)$ & $146(22)$ & $141(185)$ & $470(416)$ \\
\hline Females & $200(183)$ & $73(136)$ & $98(152)$ & $359(321)$ \\
\hline \hline Age & & $p<0.01$ & $p<0.001$ & $p<0.01$ \\
\hline
\end{tabular}




\begin{tabular}{|c|c|c|c|c|}
\hline & Walking & Other moderate activity & Vigorous activity & Total physical activity \\
\hline$\leq 35$ & $192(196)$ & $67(125)$ & $141(188)$ & $394(356)$ \\
\hline $36-55$ & $199(190)$ & $69(146)$ & $98(145)$ & $351(341)$ \\
\hline \multirow[t]{2}{*}{$>55$} & $208(196)$ & $129(189)$ & $87(122)$ & $411(332)$ \\
\hline & & $p<0.001$ & $p<0.005$ & \\
\hline \multicolumn{5}{|l|}{ Status } \\
\hline Cancer & $198(175)$ & $109(181)$ & $88(146)$ & $375(357)$ \\
\hline Non-cancer & $200(193)$ & $82(153)$ & $110(153)$ & $381(340)$ \\
\hline \multicolumn{5}{|c|}{ Family diagnosed } \\
\hline 0 & $198(185)$ & $95(162)$ & $148(186)$ & $437(362)$ \\
\hline 1 & $182(173)$ & $80(160)$ & $113(148)$ & $359(327)$ \\
\hline $2-3$ & $205(191)$ & $82(154)$ & $101(144)$ & $376(329)$ \\
\hline \multirow[t]{2}{*}{+3} & $220(224)$ & $71(122)$ & $83(137)$ & $364(355)$ \\
\hline & & & $p<0.05$ & \\
\hline \multicolumn{5}{|c|}{ Friends diagnosed } \\
\hline 0 & $189(187)$ & $63(124)$ & $99(136)$ & $346(305)$ \\
\hline 1 & $184(184)$ & 64 (107) & $114(161)$ & $350(319)$ \\
\hline $2-3$ & 215 (197) & $86(160)$ & $120(172)$ & $407(355)$ \\
\hline \multirow[t]{2}{*}{+3} & $215(191)$ & $133(218)$ & $102(130)$ & $432(370)$ \\
\hline & & $p<.01$ & & \\
\hline
\end{tabular}


The analysis of Variance (ANOVA) was conducted to compare physical activity levels across gender and age. This revealed that men engaged in more moderate $\left(F_{(1,638)}=21.502, p<0.001\right)$, vigorous $\left(F_{(1,}\right.$ $\left.{ }_{636)}=8.109, p<0.01\right)$, and total physical activity $\left(\mathrm{F}_{(1,654)}=10.540, p<0.01\right)$ than women (see Table 3$)$. The participants were grouped into three broad age ranges to facilitate examining the effect of age on health behaviors (see Table 3). This revealed differences in moderate $\left(\mathrm{F}_{(2,638)}=10.394, \mathrm{p}<0.001\right)$ and vigorous $(\mathrm{F}$ $(2,636)=6.315, p<0.01)$ physical activity across the three age groups. Post hoc analysis indicated that individuals aged $\leq 35$ years engaged in more vigorous physical activity levels than individuals aged 3655 years $(\mathrm{M}=42.86, p<0.05)$ and individuals aged less than 55 years $(\mathrm{M}=54.28, p<0.01)$. The individuals aged $>56$ engaged in more moderate physical activity than individuals aged $\leq 35$ years $(\mathrm{M}=62.69, p<0.01)$ and individuals aged $36-55$ years $(\mathrm{M}=60.28, p<0.01)$.

Differences in physical activity were also analysed separately in relation to the number of friends and family diagnosed with cancer. There was a significant difference in the amount of vigorous physical activity in terms of the number of family members diagnosed with cancer $\left(\mathrm{F}_{(3,520)}=3.170, p<0.05\right.$; Table 3$)$. The post hoc analyses revealed that individuals with more than three family members diagnosed with cancer engaged in less vigorous physical activity levels than individuals with no family members diagnosed $(\mathrm{M}=64.65$, $p<0.05)$.

There was also a significant difference in the amount of moderate physical activity in terms of the amount of friends individuals had who were diagnosed with cancer $\left(\mathrm{F}_{(3,523)}=5.030, p<0.01\right.$; Table 3$)$. The post hoc analyses indicated that individuals with more than three friends diagnosed with cancer engaged in more moderate physical activity than individuals with no friends diagnosed with cancer $(\mathrm{M}=70.13, p<0.01)$ and one friend diagnosed with cancer $(M=69.28, p<.01)$. 


\section{Health behavior changes in cancer survivors}

For individuals with a cancer diagnosis, $31.3 \%$ reported an increase in physical activity, $62.5 \%$ remained the same, and $6.3 \%$ decreased physical activity level; $50 \%$ of smokers reported quitting $(15.3 \%$ were current smokers at diagnosis) and $76.7 \%$ reported more sun-safe behaviors after their diagnosis. As evident in Table 4, the majority of cancer survivors also made positive dietary changes after their diagnosis. For example, $78.6 \%$ decreased their consumption of takeaway, $80 \%$ increased their intake of fiber, $81.3 \%$ decreased consumption of fat, and $84.6 \%$ increased fruit/vegetable consumption. Of those cancer survivors who made a positive health behavior change, most made changes within 6 months of their diagnosis. For example, $59.0 \%$ decreased fat, $69.1 \%$ decreased takeaway, $63.2 \%$ increased fiber, $72.7 \%$ increased fruit/vegetables, and $67.4 \%$ increased sun-safe behaviors within 1 month of diagnosis. Furthermore, $88.7 \%$ had decreased their fat intake, $85.5 \%$ decreased the amount of takeaway food, $89.7 \%$ increased their fiber intake, $90.9 \%$ increased their fruit/vegetable intake, and $87.0 \%$ increased their sun safe behaviors within 6 months of their diagnosis.

Table 4. Health behavior changes in cancer survivors by demographics and time since diagnosis $(N, \%)$

\begin{tabular}{|c|c|c|c|c|c|c|}
\hline & Decreased & $\begin{array}{l}\text { Increased } \\
\text { fiber }\end{array}$ & $\begin{array}{l}\text { Increased } \\
\text { fruit/vegetable }\end{array}$ & $\begin{array}{l}\text { Decreased } \\
\text { takeaway }\end{array}$ & $\begin{array}{l}\text { Increased } \\
\text { sun-safe }\end{array}$ & $\begin{array}{l}\text { Increased } \\
\text { activity }\end{array}$ \\
\hline \multicolumn{7}{|c|}{ Treatment } \\
\hline Yes & $17(81.0)$ & $17(73.9)$ & $17(81.0)$ & $15(78.9)$ & $10(71.4)$ & $9(30.0)$ \\
\hline No & $44(81.5)$ & $51(82.3)$ & $49(86.0)$ & $40(78.4)$ & $36(78.3)$ & $25(31.3)$ \\
\hline \multicolumn{7}{|c|}{ Diagnosis } \\
\hline$\leq 2$ years & $15(75.0)$ & $16(72.3)$ & $20(83.3)$ & $15(71.4)$ & $12(70.6)$ & $9(30.0)$ \\
\hline$>2$ years & $45(83.3)$ & $51(82.3)$ & $45(84.9)$ & $39(81.3)$ & $33(78.6)$ & $24(32.4)$ \\
\hline
\end{tabular}




\begin{tabular}{|c|c|c|c|c|c|c|c|c|}
\hline & $\begin{array}{l}\text { Decreased } \\
\text { fat }\end{array}$ & & $\begin{array}{l}\text { Increased } \\
\text { fiber }\end{array}$ & & $\begin{array}{l}\text { Increased } \\
\text { fruit/vegetable }\end{array}$ & $\begin{array}{l}\text { Decreased } \\
\text { takeaway }\end{array}$ & $\begin{array}{l}\text { Increased } \\
\text { sun-safe }\end{array}$ & $\begin{array}{l}\text { Increased } \\
\text { activity }\end{array}$ \\
\hline \multicolumn{9}{|l|}{ Cancer type } \\
\hline Breast & $25(86.2)$ & & $27(84.4)$ & & $26(86.7)$ & $21(80.5)$ & $17(77.3)$ & $14(34.1)$ \\
\hline Other & $31(79.5)$ & & $34(77.3)$ & & $33(84.6)$ & $28(77.8)$ & $25(78.1)$ & $16(28.1)$ \\
\hline \multicolumn{9}{|l|}{ Age } \\
\hline$\leq 55$ & $25(67.6)$ & & $28(65.1)$ & & $30(75.0)$ & $23(65.7)$ & $21(65.6)$ & $13(23.2)$ \\
\hline$>55$ & $35(94.6)$ & $* *$ & $39(95.1)$ & $* *$ & $35(94.6)$ & * $31(91.2)$ & * $24(82.8)$ & $20(38.5)$ \\
\hline \multicolumn{9}{|l|}{ Education } \\
\hline$\leq 10$ years & $18(85.7)$ & & $24(85.7)$ & & $22(88.0)$ & $18(78.3)$ & $13(72.2)$ & $11(26.2)$ \\
\hline 12 year/trade & $23(82.1)$ & & $22(73.3)$ & & $22(81.5)$ & $20(80.0)$ & $18(78.3)$ & $13(35.1)$ \\
\hline Tertiary & $19(76.0)$ & & $20(80.0)$ & & $20(83.3)$ & $16(76.2)$ & $13(76.5)$ & 8 (28.6) \\
\hline \multicolumn{9}{|c|}{ Marital status } \\
\hline Single & $18(81.8)$ & & $19(79.2)$ & & $22(79.2)$ & $17(77.3)$ & $15(75.0)$ & $10(27.8)$ \\
\hline Married & $42(80.8)$ & & 47 (79.7) & & $42(82.4)$ & $37(78.7)$ & $29(76.3)$ & $22(31.0)$ \\
\hline \multicolumn{9}{|l|}{ Job status } \\
\hline Employed & $15(71.4)$ & & $13(61.9)$ & & $15(75)$ & $13(68.4)$ & $12(70.6)$ & $7(29.2)$ \\
\hline $\begin{array}{l}\text { Not } \\
\text { employed }\end{array}$ & $45(84.9)$ & & $54(85.7)$ & * & $50(87.7)$ & $41(82.0)$ & 33 (78.6) & $26(31.0)$ \\
\hline
\end{tabular}

$$
\begin{aligned}
& * \mathrm{p}<0.05 \\
& * * \mathrm{p}<0.01 \\
& * * * \mathrm{p}<0.001
\end{aligned}
$$


Differences in health behavior changes were compared across education, marital status, employment status, cancer type, time since diagnosis, and age. Due to the low numbers of men $(n=17)$, differences in gender could not be meaningfully examined. Furthermore, differences in smoking cessation were not examined given the low number of cancer survivors who reported quitting smoking $(\mathrm{n}=10)$. To assist in examining the effects of marital status on health behavior changes, we combined the single, divorced, and widowed into one 'single' group and married and defacto into a 'married' group. No significant differences were found between groups. Similarly, there was no difference in health behavior changes depending on the time since diagnosis or education level. To compare health behavior changes as a function of age, the $\leq 35$ age group with the 36- to 55-year age group were combined given the low number of individuals $\leq 35(\mathrm{~N}=6)$. It is unlikely that this had any major bearing on the results because four of the six individuals were aged 33 to 35. These results indicated that older cancer survivors were more likely to decrease their intake of fat $\left(\chi_{(1)}^{2}=7.136, p<0.01\right)$ and amount of takeaway food $\left(\chi_{(1)}^{2}=5.161, p<0.05\right)$, and increase fiber $\left(_{(1)}^{2}=9.921\right.$, $p<0.01)$ and fruit/vegetable intake $\left(\chi_{(1)}^{2}=4.219, p<0.05\right.$; see Table 4). An effect of employment status was also observed, with more employed individuals increasing the intake of fiber compared to those not employed $\left(\chi_{(1)}^{2}=4.155, p<0.05\right)$.

\section{Health behavior changes in individuals without a cancer diagnosis}

For individuals with a friend or relative diagnosed with cancer, $24.3 \%$ reported an increase in physical activity, and $36.2 \%$ of smokers reported quitting (Table 5). The majority of individuals reported more sunsafe behavior $(59.0 \%)$ and positive dietary changes. For example, 58.5\% of individuals increased their intake of fruit and vegetables, 53.2\% decreased fat intake, 52.8\% increased fiber, and 50.4\% decreased their consumption of takeaway food. 
Table 5. Health behavior change in individuals without cancer by demographics and perceived risk of cancer $(N, \%)$

\begin{tabular}{|c|c|c|c|c|c|c|c|c|c|c|c|}
\hline & fat & & $\begin{array}{l}\text { Increased } \\
\text { fiber }\end{array}$ & & $\begin{array}{l}\text { Increased } \\
\text { fruit/vegetable }\end{array}$ & $\begin{array}{l}\text { Decreased } \\
\text { takeaway }\end{array}$ & & $\begin{array}{l}\text { Increased } \\
\text { sun-safe } \\
\text { behavior }\end{array}$ & & $\begin{array}{l}\text { Quit } \\
\text { smoking }\end{array}$ & $\begin{array}{l}\text { Increased } \\
\text { activity }\end{array}$ \\
\hline Men & $25(45.5)$ & & $25(49.1)$ & & $33(56.9)$ & $26(47.2)$ & & $32(56.9)$ & & $6(40.0)$ & $20(22.0)$ \\
\hline Women & $116(55.5)$ & & $115(54.0)$ & & $137(59.1)$ & $103(51.5)$ & & $116(59.8)$ & & $20(36.4)$ & 97 (25.2) \\
\hline \multicolumn{12}{|l|}{ Age } \\
\hline$\leq 35$ & $33(40.2)$ & & $27(33.8)$ & & $44(50.0)$ & $35(42.2)$ & & $38(49.4)$ & & $6(40.0)$ & $33(25.6)$ \\
\hline $36-55$ & $66(55.9)$ & & $71(57.3)$ & & 77 (57.9) & $57(50.4)$ & & $72(63.2)$ & & $20(36.4)$ & $51(22.7)$ \\
\hline$>55$ & $42(65.6)$ & $* *$ & $45(68.2)$ & $* * *$ & 49 (71.0) & $* 36(63.2)$ & $*$ & $35(64.8)$ & $* * *$ & $7(50.0)$ & $33(27.0)$ \\
\hline \multicolumn{12}{|l|}{ Education } \\
\hline$\leq 10$ years & $52(56.5)$ & & $50(54.9)$ & & $60(61.2)$ & $42(51.2)$ & & $43(56.6)$ & & $6(28.6)$ & $39(23.4)$ \\
\hline 12 years/trade & $39(44.3)$ & & $41(46.6)$ & & $52(52.5)$ & $41(46.6)$ & & 47 (56.0) & & $11(39.3)$ & $42(27.3)$ \\
\hline Tertiary & $48(58.5)$ & & $50(56.8)$ & & $56(62.2)$ & $43(53.8)$ & & $53(64.6)$ & & $8(40.0)$ & $34(22.7)$ \\
\hline \multicolumn{12}{|l|}{ F/Friends } \\
\hline$\leq 3$ & $55(47.8)$ & & $53(45.7)$ & & $65(52.8)$ & $48(43.2)$ & & 57 (53.3) & & $10(31.3)$ & $43(22.2)$ \\
\hline $3+$ & $86(57.7)$ & & $90(58.4)$ & $* * * *$ & 105 (62.9) & $80(56.3)$ & $* * * *$ & $88(63.8)$ & & $15(40.5)$ & $72(25.7)$ \\
\hline \multicolumn{12}{|l|}{ Marital } \\
\hline Single & $38(46.9)$ & & $38(45.2)$ & & 49 (54.4) & $38(47.5)$ & & $40(53.3)$ & & $10(38.5)$ & $30(26.0)$ \\
\hline Married & $102(55.7)$ & & $104(56.2)$ & & $120(60.3)$ & 89 (51.7) & & $104(61.5)$ & & $15(34.9)$ & $76(23.5)$ \\
\hline \multicolumn{12}{|l|}{ Risk } \\
\hline Less & 17 (48.6) & & 27 (48.6) & & $20(51.3)$ & $13(39.4)$ & & $15(46.9)$ & & $4(50.0)$ & 17 (26.6) \\
\hline Average & $86(52.4)$ & & $85(52.5)$ & & $102(58.6)$ & $72(48.3)$ & & $80(56.7)$ & & $13(32.5)$ & $60(20.2)$ \\
\hline More & $37(57.8)$ & & $40(56.3)$ & & $46(62.2)$ & $42(60.9)$ & & $49(70.0)$ & $* * * *$ & 7 (38.9) & $35(33.3)$ \\
\hline \multicolumn{12}{|l|}{ Job status } \\
\hline Employed & $102(57.3)$ & & $97(54.5)$ & & $112(60.2)$ & $88(52.7)$ & & $92(59.0)$ & & $13(31.7)$ & $80(26.1)$ \\
\hline
\end{tabular}




\begin{tabular}{|c|c|c|c|c|c|c|c|c|}
\hline & fat & & $\begin{array}{l}\text { Increased } \\
\text { fiber }\end{array}$ & $\begin{array}{l}\text { Increased } \\
\text { fruit/vegetable }\end{array}$ & $\begin{array}{l}\text { Decreased } \\
\text { takeaway }\end{array}$ & $\begin{array}{l}\text { Increased } \\
\text { sun-safe } \\
\text { behavior }\end{array}$ & $\begin{array}{l}\text { Quit } \\
\text { smoking }\end{array}$ & $\begin{array}{l}\text { Increased } \\
\text { activity }\end{array}$ \\
\hline $\begin{array}{l}\text { Not } \\
\text { employed }\end{array}$ & $38(44.2)$ & **** & $45(49.5)$ & $57(55.3)$ & $39(45.9)$ & $52(59.1)$ & $11(40.7)$ & $35(21.0)$ \\
\hline
\end{tabular}

$* \mathrm{p}<0.05$

$* * \mathrm{p}<0.01$

$* * * \mathrm{p}<0.001$

$* * * * \mathrm{p}<0.06$

Differences in health behavior changes were again examined as a function of age, gender, education, perception of cancer risk, marital status, work status, and the number of friends or family diagnosed with cancer. As the age increased the proportion of individuals reporting positive changes in health also increased. This occurred for a significant decrease in fat $\left(\chi_{(2)}^{2}=9.851, p<0.01\right)$ and a near significant decrease in takeaway food $\left(\chi_{(2)}^{2}=5.958, p=.051\right)$. There were also significant increases in fiber intake $\left(\chi^{2}{ }_{(2)}\right.$ $=18.908, p<0.001)$, fruit/vegetables $\left(\chi_{(2)}^{2}=7.094, p<0.05\right)$, and sun-safe behaviors $\left(\chi_{(2)}^{2}=25.704, p<0.001\right)$ with age (Table 5).

There were no differences in health behavior changes as a function of gender, marital status or education level (see Table 5). Individuals with a greater perceived risk of cancer showed a trend to increasing sun-safe behaviors $\left(\chi_{(2)}^{2}=5.749, p=0.056\right)$ and were also more likely to increase their physical activity levels $\left(\chi^{2}(2)\right.$ $=7.586, p<0.05)$. The effects of the number of family members and friends diagnosed with cancer were initially examined separately, and no differences in health behaviour changes were noted. This could have been confounded because participants who knew of friends diagnosed with cancer tended to also have family members diagnosed with cancer. Hence, the effects of the number of friends and family diagnosed with cancer could not be meaningfully separated. As a consequence, we combined the number of friends and 
family diagnosed with cancer. The results indicated that knowing more than three family members or friends with a cancer diagnosis led to a near significant increase in fiber intake $\left(\chi_{(1)}^{2}=3.822, p=0.051\right)$ and a near significant decrease in takeaway food $\left(\chi_{(1)}^{2}=3.766, p=0.052\right)$.

\section{A comparison of health behavior changes}

In the final stage of analysis, health behavior changes were compared between cancer survivors and friends/family of cancer survivors. Changes in physical activity levels and smoking behavior did not differ significantly between individuals with and without a cancer diagnosis. However, cancer survivors increased their sun-safe behaviors compared to participants without a cancer diagnosis $\left(\chi_{(1)}^{2}=21.026, p=0.000\right)$. Cancer survivors also differed significantly from non-cancer participants in terms of the proportion who decreased fat consumption $\left(\chi_{(1)}^{2}=19.321, p=0.000\right)$, increased fiber consumption $\left(\chi_{(1)}^{2}=18.897, p=0.000\right)$, increased fruit/vegetables $\left(\chi_{(1)}^{2}=16.721, p=0.000\right)$, and decreased amount of takeaway $\left(\chi_{(1)}^{2}=18.414\right.$, $p=0.000)$. This indicated that cancer survivors made more positive dietary changes compared to non-cancer family and friends (Table 6).

Table 6. A comparison of health behavior changes in individuals with and without a cancer diagnosis

\begin{tabular}{|l|l|l|l||}
\hline Health behavior change & Cancer & Non-cancer & Significance \\
\hline Decreased fat & $61(82.4)$ & $141(53.9)$ & $* * *$ \\
\hline Increased fiber & $66(80.5)$ & $143(53.1)$ & $* * *$ \\
\hline Increased fruit/vegetable & $65(84.4)$ & $170(58.5)$ & $* * *$ \\
\hline Decreased takeaway & $56(80.0)$ & $128(50.4)$ & $* * *$ \\
\hline Increased sun-safe & $45(77.6)$ & $145(59.0)$ & $* * *$ \\
\hline Quit smoking & $10(50.0)$ & $25(36.2)$ & ns \\
\hline
\end{tabular}




\begin{tabular}{|l|l|l|l|}
\hline Health behavior change & Cancer & Non-cancer & Significance \\
\hline Increased physical activity & $33(30.6)$ & $115(32.0)$ & ns \\
\hline
\end{tabular}

$* * * p<0.001$

\section{Discussion}

Several studies have reported that many cancer survivors engage in unhealthy behaviors such as poor diet and low physical activity levels $[15,18]$ that could increase their risk of other chronic disease. However, few prior studies have specifically asked about changes in dietary intake and physical activity since their cancer diagnosis as opposed to current prevalence rates. The relevant studies that have done this suggest that cancer survivors appear motivated to improve their health behaviors and that some do make health behavior changes. Lemon et al. [25] also suggested that the diagnosis of cancer could motivate the family of cancer survivors to make health behavior changes. The aim of this study was to further explore the effect of a cancer diagnosis on the health behaviors of the survivor and their family and close friends.

An increased consumption of fruit and vegetables was reported by $84 \%$ of the cancer survivors in this study. This positive finding is comparable to the results obtained by Maunsell and colleagues [28], where $72 \%$ of participants increased their consumption, but is much higher than the $45 \%$ reported by Patterson et al. [34]. This study also found that a much higher proportion of participants had decreased the amount of fat in the diet compared to the Patterson sample (81 versus $28.5 \%$ ). Questions used in this study were similar to the Blanchard et al. [9] study making results more comparable. Comparison of results for this study and the Blanchard study respectively include the following: $15.3 \%$ of the survivors were current smokers with $50 \%$ quitting compared to $18 \%$ with $46 \%$ quitting, $81 \%$ reduced fat intake compared to $50.6 \%$, $80 \%$ increased fiber intake compared to $43.5 \%$, and $31 \%$ increased exercise compared to $15.7 \%$. 
The results of the current study, therefore, indicate that a substantial proportion of cancer survivors made positive health behavior changes after their diagnosis. Of those who made a positive health behavior change, most made this change within 6 months of diagnosis. Age was consistently associated with improving dietary behaviors, and like prior studies [9, 34], no significant differences were found between men and women. The variables that had not been previously examined for association with behaviour change following a cancer diagnosis, such as marital and work status, were not found to influence changes in health behaviour.

Differences across studies could reflect different demographics because the majority of cancer survivors in the current study were diagnosed with breast cancer. Although we did not find any evidence for differences in behavior changes due to cancer type, this could be due to a small proportion of other cancer types. For example, Patterson et al. [34] examined equal proportions of breast, prostrate, and colon cancer. It is possible that health behavior changes differ across cancer types, and this should be further examined in future studies. There were also differences in recruitment strategies across studies. The sample in this study could have perhaps been more motivated as the recruitment strategy was proactive (survey had to be returned by mail), whereas the Patterson sample was contacted by telephone, and the Blanchard sample was approached in clinics.

These results suggest that cancer survivors may be motivated to make positive dietary changes to improve their health. Cancers survivors were asked to self-report whether or not they had increased exercise levels after their cancer diagnosis, and 31.3\% reported an increase. Survivors (71.7\%) reported currently taking part in enough physical activity to meet the recommended guidelines for health benefits $[12,45]$. This is much higher than the $25 \%$ reported by Bellizza et al. [8]. However, these authors asked about frequency and duration of moderate and vigorous activities conducted on at least 5 days week, whereas the current study additionally asked about frequency and duration of walking activity. These variations in measurement across 
studies could have contributed towards the diverse results and may have resulted in the over-reporting of total physical activity in the current study. However, the active Australia survey has reported adequate testretest reliability [3]. It is also possible that the current sample could reflect a group that is more active than the general population. The results were more comparable to a study of breast cancer survivors, where $42 \%$ reported having increased exercise participation due to their cancer, and $67 \%$ currently engaged in a moderate intensity exercise [37].

A diagnosis of cancer did appear to act as a 'teachable moment' for increasing physical activity among this sample of cancer survivors. However, the majority of cancer survivors maintained the same level and a small proportion even decreased physical activity post diagnosis. This is concerning because physical activity is a practical and effective way to combat many side effects of cancer treatment and also to improve quality of life [31-33]. It is possible that many health practitioners encourage cancer survivors to make positive changes in their diets and to quit smoking, but may not be as encouraging with regards to physical activity. The importance of physical activity after a cancer diagnosis may not be as widely recognized as dietary change. Alternatively, dietary changes may seem easier to cancer survivors and may be viewed as more crucial for protection from risk of further illness compared to physical activity. The non-cancer group was younger than the cancer group, and this could explain why changes in physical activity did not differ significantly, whereas the cancer group made many more dietary changes.

The secondary aim of the current study was to determine whether cancer diagnosis served as a teachable moment or a 'cue to action' for the friends and family of cancer survivors to improve health behaviors. A strength of this study was that $81.3 \%$ of the participants reported having one or more immediate family members and $68.6 \%$ having at least one friend diagnosed with cancer. This resulted in a unique opportunity to compare any changes in health behaviors of family and friends against those of cancer survivors. 
For individuals with a friend or relative diagnosed with cancer, the majority made improvements to their diet. This would suggest that the diagnosis of cancer does motivate the friends and family of cancer survivors to make positive dietary changes (50 to 59\%) and is consistent with, although a lot higher than, the trends observed by Lemon et al. [25] in FDFR (20 to 22\%). However, more cancer survivors made positive dietary changes compared to the friends and family of the cancer survivors, which suggests that cancer had more impact on the survivor as would be expected.

We also found that $24 \%$ of the friends and family reported an increase in physical activity, and $36 \%$ of those who smoked had quit. These results are more consistent with the increases in physical activity (25\%) and smoking cessation (21\%) reported by Lemon et al. [25]. The differences in physical activity levels between the cancer survivors and the non-cancer participants were not significant.

The number of family members or friends was not found to influence changes to health behaviors in family and friends, and as for the cancer group, significant differences were found by age, but not by gender or education level. Although smaller proportions of the non-cancer group reported making changes to health behaviors as would be expected compared to the cancer survivors themselves, quite substantial improvements in diet were reported. Again, dietary changes may seem easier and may be viewed as crucial for protection from risk compared to increasing their physical activity habits. A possible explanation for the greater proportion reporting dietary change among the older age group is the high salience of their mortality, and/or the likely age of known family member/friends diagnosed.

Interestingly, a greater proportion of family and friends who perceived they were at greater risk of developing cancer themselves had increased physical activity and sun-smart behavior but had not improved dietary habits, although a trend in this direction was shown. Contrary to expectations, the length of time since the family member or friend was diagnosed was not found to be predictive. 
There were several limitation to this study. Respondents were attending a walking event, and this could have resulted in a sample that was motivated to improve health behaviors. However, this gave us access to a large number of non-cancer people associated with individuals that did have cancer. The proportion of respondents with cancer was much smaller than the proportion without cancer, and the majority of respondents were women with breast cancer. This limited some analyses and may also limit the generalizability of findings.

\section{Conclusions and future research}

The health belief model could serve as a useful framework for future research investigating health behavior changes in family and friends of cancer survivors [23]. This model posits that health behavior changes are influenced by a range of psychological factors, such as 'self-efficacy', 'perceived susceptibility', and 'cues to action'. The current results suggest that 'perceived susceptibility' could have been related to increased physical activity and improved sun-safe behavior. It is also possible that important 'cues to action' such as the effect of the media and cancer symptoms could also be important within the context of cancer as a 'teachable moment'. These factors should be addressed in future research.

For the sample in this study, a personal diagnosis of cancer, or a diagnosis in a family member or friend, may have acted as a 'cue to action' to improve lifestyle health behaviors. This field of research is still at an early stage, and further studies are needed to confirm if this situation could be useful as a 'teachable moment' for intervention purposes. Longitudinal studies, in particular, will gauge more accurately any changes made since diagnosis. A cancer diagnosis may be an advantageous moment for an effective intervention as motivation to change lifestyle behaviors may be heightened. Whether it can be a 'teachable moment' in family and friends will depend on the extent to which the cancer diagnosis prompts a strong emotional response, whether the individual's perception of their risk for cancer increases, and whether they believe a behavior change will help reduce the risk. 


\section{Acknowledgment}

We are grateful to the Cancer Council NSW both for its financial support and access to potential participants for this study.

\section{References}

1. American Cancer Society (2004) Cancer facts and figures. http://www.cancer.org/downloads/STT/CAFF_finalPWSecured.pdf

2. Andrykowski M, Beacham A, Schmidt J, Harper K (2006) Application of the theory of planned behavior to understand intentions to engage in physical and psychosocial health behaviors after cancer diagnosis. Psycho-Oncol 15:759-771.

3. Armstrong T, Bauman A, Davies J (2000) Physical activity patterns of Australian adults. Results of the 1999 National Physical Activity Survey. Australian Institute of Health and Welfare, Canberra.

4. Audrain J, Schwartz M, Herrera J, Goldman P, Bush A (2001) Physical activity in first-degree relatives of breast cancer patients. J Behav Med 24:587-603.

5. Australian Institute of Health and Welfare (2004) National Cancer Statistics Clearing House. http://www.aihw.gov.au.ezproxy.uow.edu.au/cancer/ncsch/index.html

6. Baade PD, Fritschi L, Eakin EG (2006) Non-cancer mortality among people diagnosed with cancer. Cancer Causes Control 17(3):287-297.

7. Baker F, Denniston M, Smith T, West M (2005) Adult cancer survivors: how are they faring? Cancer 104:2565-2576.

8. Bellizzi KM, Rowland JH, Jeffery DD, McNeel T (2005) Health behaviors of cancer survivors: examining opportunities for cancer control intervention. J Clin Oncol 23:8884-8893.

9. Blanchard C, Denniston M, Baker F, Ainsworth S, Courneya K, Hann D, Gesme D et al (2003) Do adults change their lifestyle behaviors after a cancer diagnosis? Am J Health Behav 27:246-256. 
10. Booth ML, Owen N, Bauman A, Gore CJ (1996) Relationship between a 14-day recall measure of leisure time physical activity and a submaximal test of physical work capacity in a population sample of Australian adults. Res Q Exerc Sport 67:221-227.

11. Booth ML, Owen N, Bauman A, Gore CJ (1996) Retest reliability of recall measures of leisure-time physical activity in Australian adults. Int J Epidemiol 25:153-159.

12. Commonwealth Department of Health and Aged Care (1999) National physical activity guidelines for Australians. Australian Government Publishing Service, Canberra.

13. Coups E, Ostroff J (2005) A population-based estimate of the prevalence of behavioral risk factors among adult cancer survivors and noncancer controls. Prev Med 40:702-711.

14. Courneya K (2003) Exercise in cancer survivors: an overview of research. Med Sci Sports Exerc $35: 1846-1852$.

15. Courneya K, Friedenreich C (1997) Relationship between exercise pattern across the cancer experience and current quality of life in colorectal cancer survivors. J Altern Complement Med 3:215-266.

16. Deimling GT, Kahana B, Bowman KF, Schaefer ML (2002) Cancer survivorship and psychological distress in later life. Psycho-Oncol 11:479-494.

17. Demark-Wahnefried W, Aziz N, Rowland JH, Pinto B (2005) Riding the crest of the teachable moment: promoting long-term health after the diagnosis of cancer. J Clin Oncol 23:5814-5830.

18. Demark-Wahnefried W, Peterson B, McBride C, Lipkus I, Clipp E (2000) Current health behaviors and readiness to pursue life-style changes among men and women diagnosed with early stage prostate and breast carcinomas. Cancer 88:674-684.

19. Dimeo F, Stieglitz R, Novelli-Fischer U, Keul J (1999) Effects of physical activity on the fatigue and psychological status of cancer patients during chemotherapy. Cancer 85:2273-2277.

20. Hervouet S, Savard J, Simard S, Ivers H, Laverdiere J, Vigneault E, Fradet Y, Lacombe L (2005) Psychological functioning associated with prostate cancer: cross-sectional comparison of patients treated with radiotherapy, brachytherapy, or surgery. J Pain Symptom Manage 30:474-484. 
21. Hewitt M, Rowland JH, Yancik R (2003) Cancer survivors in the United States: age, health, and disability. J Gerontol 58A:82-91.

22. Hickok JT, Morrow GR, Roscoe JA, Mustian K, Okunieff P (2005) Occurrence, severity, and longitudinal course of twelve common symptoms in 1129 consecutive patients during radiotherapy for cancer. J Pain Symptom Manage 30:433-442.

23. Janz N, Champion V, Strecher V (2002) The health belief model. In: Glanz K, Rimer B, Lewis F (eds) Health behavior and health education: theory, research, and practice, 3rd edn. Jossey-Bass, San Francisco, pp 45-66.

24. Kristeller J, Hebert J, Edmiston K, Liepman M, Wertheimer M, Ward A, Luippold R (1996) Attitudes toward risk factor behavior of relatives of cancer patients. Prev Med 25:162-169.

25. Lemon SC, Zapka JG, Clemow L (2004) Health behavior change among women with recent familial diagnosis of breast cancer. Prev Med 39:253-262.

26. MacVicar M, Winningham M, Nickel J (1989) Effects of aerobic interval training on cancer patients' functional capacity. Nurs Res 38:251-348.

27. Madlensky L, Vierkant RA, Vachon CM, Pankratz VS, Cerhan JR, Vadaparampil ST, Sellers TA (2005) Preventive health behaviors and familial breast cancer DOI 10.1158/1055-9965.EPI-05-0254. Cancer Epidemiol Biomark 14:2340-2345.

28. Maunsell E, Drolet M, Brisson J, Robert J, Deschenes L (2002) Dietary change after breast cancer: extent, predictors, and relation with psychological distress. J Clin Oncol 20:1017-1025.

29. McBride C, Emmons K, Lipkus I (2003) Understanding the potential of teachable moments: the case of smoking cessation. Health Educ Res 18:156-170.

30. McKee J (1994) Cues to action in prostate cancer screening. Oncol Nurs Forum 21:1171-1176.

31. Mock V, Hassey Dow K, Meares C, Grimm P, Dienemann J, Haisfield-Wolfe M, Quitasol W et al (1997) Effects of exercise on fatigue, physical functioning, and emotional distress during radiation therapy for breast cancer. Oncol Nurs Forum 24:991-1000. 
32. Mock V, Pickett M, Ropka M, Lin E, Stewart K, Rhodes V et al (2001) Fatigue and quality of life outcomes of exercise during cancer treatment. Cancer Pract 9:119-127.

33. Oldervoll LM, Kaasa S, Hjermstad MJ, Lund JA, Loge JH (2004) Physical exercise results in the improved subjective well-being of a few or is effective rehabilitation for all cancer patients? Eur J Cancer 40:951-962.

34. Patterson RE, Neuhouser ML, Hedderson MM, Schwartz SM, Standish LJ, Bowen DJ (2003) Changes in diet, physical activity, and supplement use among adults diagnosed with cancer. J Am Diet Assoc 103:323-328.

35. Pinto B, Clark M, Maruyama N, Feder S (2003) Psychological and fitness changes associated with exercise participation among women with breast cancer. Psycho-Oncol 12:118-126.

36. Pinto B, Eakin E, Marumaya N (2000) Health behavior changes after a cancer diagnosis: what do we know and where do we go from here? Ann Behav Med 22:38-52.

37. Pinto B, Maruyama N, Clark M, Cruess D, Park E, Roberts M (2002) Motivation to modify lifestyle risk behaviors in women treated for breast cancer. Mayo Clin Proc 77:122-129.

38. Pinto B, Trunzo J (2005) Health behaviors during and after a cancer diagnosis. Cancer 104:2614-2623.

39. Pinto B, Trunzo J, Reiss P, Shui S (2002) Exercise participation after diagnosis of breast cancer: trends and effects on mood and quality of life. Psycho-Oncol 11:389-400.

40. Rabin C, Pinto B (2006) Cancer-related beliefs and health behavior change among breast cancer survivors and their first-degree relatives. Psycho-Oncol 15:701-712.

41. Raison CL, Miller AH (2003) Depression in cancer: new developments regarding diagnosis and treatment. Biol Psychiatry 54:283-294.

42. Satia J, Campbell M, Galanko J, James A, Carr C, Sandler R (2004) Longitudinal changes in lifestyle behaviors and health status in colon cancer survivors. Cancer Epidemiol Biomark 13:1022-1031.

43. Schwartz M, Lerman C, Miller S, Daly M, Mansy A (1995) Coping disposition, perceived risk, and psychological distress among women at increased risk for ovarian cancer. Health Psychol 14:232-235. 
44. Tracey E, Roder D, Bishop J, Chen S, Chen W (2005) Cancer in New South Wales: incidence and mortality 2003. NSW Cancer Institute, Sydney.

45. USDHHS (1996) Physical activity and health: a report of the Surgeon General. US Department of Health and Human Services, Centers for Disease Control and Prevention, National Center for Chronic Disease Prevention and Health Promotion, Atlanta. 